\title{
ON THE NATURE AND TREATMENT OF CANCER.
}

\author{
By ALEXANDER URE, Esq., Surgeon to St. Mary's Hospital.
}

(Read at the Harveian Society, April 15, 1852.)

THE elements of every cancerous growth are the cells of cancer, intermixed with the structure of any of the tissues which compose the body. The result of this is the substitution of a new, for the natural tissue of the part.

The cancer cell is remarkable for its multiform character. No one shape is to be considered as certainly and alone characteristic; on the contrary, it will be found that the cancer cell affects a variety of forms. That these different forms are only modifications, is insisted upon by M. Lebert, who, in his Practical Treatise on Cancerous Maladies, and on Curable Affections which may be confounded with Cancer, published last year, says: "The type of the cancer cell is a small regular sphere, with an elliptical nucleus, occupying about half of the interior of the cell, and containing one or more nucleoli; but that type is not often distinct. The cellular envelope takes the ovoid, triangular, heart, and caudate shape. . . . It would be useless to recount here all the shapes assumed by the cancer cell; it is sufficient to remark, that in no other cell do we observe this multiformity of the cell wall to the same degree."

The nucleus, according to this author, is the constant element of the cancer cell. I believe, however, that many cancer cells will be met with, in which no nucleus is to be discerned.

Cancer is to be regarded as a specific malady. It is to be met with in almost every tissue of the human frame. It assails alike skin, mucous membrane, muscles, fibrous tissue, and nerve, and is even deposited in the medullary cavities of bones. It has a marked tendency to spread in all directions, and to return again when removed, either in the place it originally occupied, or in some other part of the body. It eventually contaminates, so to speak, the whole animal economy, and thus induces decay and dissolution.

Cancerous tumours may be arranged for the convenience of study into two groups; first, the scirrhus or hard cancer; second, the medullary, encephaloid, or soft cancer. These seem to differ from each other merely in the presence of a greater or less proportion of fibrous tissue ; many fibres and few cells constituting scirrhus, few fibres and many cells forming medullary. Scirrhus, as is well observed by Mr. Brinton, ${ }^{1}$ cannot be accurately distinguished from fibrous tumours by the unassisted eye ; in reality, scirrhus is a fibrous tumour with one element superadded, and that element is the cells of cancer. The arrangement of these cells is peculiar; they may either be intermixed, or else accumulated in cysts.

In medullary cancer, the cells are in great abundance; and, in consequence, the proportionate absence of fibrous tissue renders the whole tumour much softer, approaching in consistency the brain of a child.

1 Medical Examiner. Philadelphia : Nov. 1851, p. 718. 
Scirrhous and medullary cancer may exist together; or rather scirrhus has a natural tendency to merge into medullary, by the more rapid development of cells; so that we often find both of these forms of cancer united in a single tumour.

The other forms of cancer which have been described by pathologists, such as the colloid, the melanoid, the hæmatoid, and the like, are to be reckoned as merely varieties, with another element superadded. Thus, the colloid or endogenous form consists of cancer cells imbedded in a gelatiniform substance of the nature of pyine; the melanoid is composed of cancer cells associated with brownish-black pigment-corpuscles; the hæmatoid, of cancer cells admixed with blood.

I omit here the consideration of the so-called epithelial cancer, as it is my intention to make it the subject of future research. Although included by some writers among cancers, it presents many points of dissimilarity. It contains none of the characteristic cells belonging to cancer, in the strict sense of the term. It consists essentially of epithelium scales, for the most part flattened, sometimes cylindrical. Its morbific influence seems to be arrested at the adjoining lymphatic glands; when extirpated, analogous growths are never met with subsequently in important internal organs, in the future progress of the disease.

Cancerous tumours are supplied by arteries, veins, and capillary vessels. The vascular distribution varies in different tumours, nay, even in different portions of the same tumour. According to $M$. Lebert, neither nerves nor lymphatics have as yet been detected in tumours of this description. But, although the eye of the anatomist may have failed to discern their presence, it seems highly probable that the nerves distributed to the part in which the cancer is situate, may have become 80 modified by the morbid infiltration as to elude discovery, and be yet the medium of those agonising sensations, so frequently experienced by patients afflicted with the disease.

Examined chemically, cancer is found to consist of albuminoid and fibrinous substance, of different kinds of fat and of caseine, but the albuminoid constituent predominates. The "cancer juice", the liquid which permeates the cancerous structure, and holds in suspension the cancer cells, is usually, according to $\mathbf{M}$. Lebert, of a pale yellow hue, inclining to white. It is sometimes red, from admixture with blood; brown or black, from the presence of melanotic pigment; thick, and of a dingy yellow tint, when containing much fat. It forms an emulsion with water, rendering the latter uniformly turbid.

The origin of cancer is veiled in obscurity. The presumption is, that the blastema is elaborated from the blood, because, wherever capillary vessels exist, there cancer may spring up. The blood thus becomes the vehicle of the cancerous predisposition, but is not transformed directly into cancer in the vessels. At least we have no evidence of the fact. When, for instance, cancer has been met with in the veins, it has either penetrated the coats of the vessel from without inwards, or else a germinal particle has been deposited on the internal membrane, and there maturated under favourable conditions. It would appear that, for a certain period, the constitution is able to withstand the development of cancer, until from some cause the vital energy is lowered; and then the slightest external injury is sufficient to quicken 
the nascent germ, and rouse it into activity. The effect may be likened to that of catalytic agency, to which 80 many remarkable phenomena in organic chemistry have been ascribed.

The first minute drop of cancerous exudation is distinctly cancerous, and reveals the peculiar cells. In proportion as it increases, it receives vessels which proceed from those in the vicinity; it is thus for some time nourished and augmented by fresh exudation of blastema, and not, as has been supposed, by cellular growth, the result of a special generation of cells. The production of cells is to be viewed merely as the effect, and not the cause, of a perversion of nutrition, of an aberration of the formative process.

M. Maisonneuve, in a late number of the Gazette des Hopitaux, has suggested the idea, that the cancerous molecules, too large to pass off by the natural emunctories, are stopped in the capillaries, where they become the nucleus for new products. This hypothesis is, however, without proof.

Two stages may be generally recognised in the progress of cancer. The first is that of evolution; the second that of disintegration. In the first we have the primal exudation, followed by the growth and vascularity of the resulting adventitious structure. This may continue until death. The second stage is characterised by the different changes to be met with in the morbid growth. Among these may be included softening and ulceration, extravasation of blood, circumscribed inflammation with the formation of abscess, and even of gangrene. The internal degeneration of the cancer cells by infiltration of a granular fatty substance, pointed out by $\mathbf{M}$. Lebert, and which is denoted by a meshy appearance, may, when very extensive, determine atrophy of the cancer. With the advance of the atrophy, the whole morbid mass may waste away, and leave an irregular cicatrised surface in its stead. This may convey the impression that a cure is being accomplished. Generally speaking, however, the cure is only limited to the spot, and but of brief duration. A curious phenomenon occasionally met with during the gradual disintegration of a cancer, is the production of a bony substance, which is separated in small amorphous marly masses. This may be referred to the law of attraction of similar parts. I submitted to microscopic examination a section of one of these nodules, but failed to discover any bony corpuscles. The section had a striated appearance, the result probably of calcification of the fibrous texture.

It is believed by many intelligent surgeons that a tumour of an innocent nature may, in the course of time, degenerate into cancer. Such is not the fact. A fatty or fibrous tumour may undoubtedly become the receptacle of cancer, in common with any other organised texture of the body, but not independently of a preexistent cancerous tendency in the system.

It has been above stated that cancer manifests a proneness to spread. The fibrous structures, the arteries, and the cartilages, are those which resist the longest its destructive influence. The cellular tissue, the lymphatic vessels, and the reins, afford ready means of diffusing the disease. The mode of extension is first to the adjunct textures; then to neighbouring organs; and next, by the medium of the lymphatic vessels, to the glands in the vicinity. 
As the disease advances, the constitution becomes impaired, and death is the inevitable result.

It may be laid down as an indisputable fact, that, in the present state of science, cancer is quite incurable. But is the surgeon, on this account, to abandon the patient entirely to his fate? Certainly not; he may palliate where he cannot cure.

The plan chiefly resorted to for the removal of external cancers is the operation by the knife. This expedient ought only to be adopted where the surgeon has a well-grounded hope of abating the suffering without shortening the life of the patient; otherwise it is unjustifiable. Many condemn the operation, without taking into account the relief which it frequently affords. It is no uncommon thing to see patients from whom a cancer has been opportunely extirpated, recover a healthful complexion, regain their strength and spirits, and cease to suffer for several years. Even in less successful cases, that is, where life has not been apparently prolonged, the patients have been exempted from a painful, a loathsome, and a lingering death. Moreover, if there be good reason to believe, that the local malady, in proportion as it gains ground, increases the tendency to infection of the system, it is evident that a patient who has undergone the operation is in nearly the same condition as an individual simply predisposed, and without any manifest cancerous development.

The surgeon, therefore, may conscientiously operate, when there is a clear prospect of removing the whole of the adventitious structure; when the disease is established, and making distinct progress, and the pain very distressing. Scirrhous tumours are less prone to relapse at an early period than those of the encephaloid type. The operation is contra-indicated when well-marked signs of cancerous cachexia are present, and when other tumours are perceived at some distance from the original seat of the malady. If the breast be the organ affected, an operation is objectionable, when the tumour is adherent to the skin or to the walls of the chest, when the nipple is retracted, and when the lymphatic glands, more especially those near the clavicle, are implicated in the disease.

One would be less disposed to operate on a person stricken in years, than on one at a less advanced period of life; and, although it is in general advisable not to delay the operation, still an exception may be made in the case where the patient suffers scarcely any inconvenience, where the progress of the tumour is very slow, and there is no obvious tendency to spread by radiation.

In performing the operation, the fundamental rule is to remove every portion of the diseased structure, and to ensure this, the whole extent of the wound ought to be carefully searched, in order that none be left. Whenever practicable, it is important that the edges of the wound be brought into direct apposition, and thus retained, so as to procure immediate union. After the wound is healed, the application of collodion is useful in promoting the contraction and prompt consolidation of the cicatrix. It likewise shields the tender cuticle from the air, and from risk of abrasion. With this view the collodion is to be pencilled over the surface, twice or thrice a week regularly, for some time. $I$ was led to adopt the practice from observing that patients very often feel uneasiness in the cicatrix on change of weather, and also that 
secondary cancerous deposits are frequently met with in that situation. Hence the propriety of obviating every source of local uneasiness or pain in individuals of a cancerous habit. In the two following cases, the collodion was employed as above directed.

Case. A stout married woman, who had never been a mother, thirtyfour years of age, applied to me in the month of September 1849, on account of a large, irregular, and hard swelling, occupying the upper portion of the left mamma, which was very fully developed. There was, besides, some swelling, with tenderness on pressure, along the anterior border of the axilla. The tumour was first perceived about four and a half years previously, of the bigness of a pea, in the axillary side of the mamma. About a year and a half from the above date, after a blow received on the breast, the tumour began to enlarge, and become the seat of pain. The pain was like that of the stab of a knife, was experienced mostly on change of weather, and created a feeling of nausea after taking food. It was felt chiefly in the bone of the shoulder, and underneath the mammary gland. During the six months previous to my seeing this patient, the tumour had been rapidly increasing in size. By the application of leeches, and of a cooling lotion, the swelling and uneasiness near the axilla subsided. On the 14th of September 1849, I removed the tumour in the ordinary way by two elliptical incisions. The tumour was bulky, and, weighed along with the fat which surrounded it, upwards of eight ounces. It was in some parts softened; it had the unequivocal characters of carcinoma.

As soon as cicatrisation was completed, the collodion was steadily applied for several months. Up to the present time, she has no apparent return of the malady.

CAsE. A widow, thirty-six years of age, of a robust frame and healthful look, the mother of one child, consulted me, in the autumn of 1849, respecting a swelling seated in the right breast. The swelling had a soft but uneven feel; was about as large as a pullet's egg, quite moveable, and situate in the outer and upper portion of the mamma. She suffered from pain referred to the nipple, and also darting down the right arm as far as the forefinger. Latterly she had been annoyed with puffy swelling of the right hand, and a sense of aching when she did any needlework; she was thus prevented from pursuing her calling, that of a dressmaker. She first perceived the swelling eighteen months previously; six months afterwards the pain supervened. The catamenia had continued uniformly regular. Various means were tried for the purpose of dispersing the tumour, but without advantage. On the 12th October 1849, I removed the tumour, as in the preceding case, by two elliptical incisions. The tumour, which was examined both by Mr. Quekett and myself, was distinctly scirrhous. The cicatrix was treated with collodion. I have seen this patient during the present week. She is exempt from any manifestation of cancerous disease, and labours busily in her vocation.

It is satisfactory to find that both of these patients have now sur. vived the operation for upwards of two years and a half, without any apparent return of cancerous disease. One has already outlived the average term assigned to individuals afflicted with scirrhus, namely, four years; while the other has exceeded that term by a period of 
three years; a circumstance the more remarkable in the case last referred to, for the condition of the patient was by no means favourable, inasmuch as the tumour was partially softened, and would have ere long caused ulceration of the superincumbent integument, as was indeed indicated by a dusky red spot on the skin.

As a general rule, excision is the most eligible mode of extirpating cancerous tumours. The operation, moreover, since the introduction of chloroform, is without pain. Nevertheless, the surgeon will occasionally meet with cases in which the employment of the knife is inadmissible, or where, if admissible, the patient refuses to submit to it. Under such circumstances, resort may be had to the escharotic plan of treatment, provided the disease be circumscribed. One of the most efficient escharotics is the chloride of zinc. Its application, however, is attended with much pain. Several years ago, in some researches on cancer, published in the Medical Gazette, I pointed attention to the fact, that chloride of zinc has a remarkable affinity for albumen, and, in virtue of this affinity, sought to explain its action when placed in contact with cancerous growths, which are composed in a great measure of that proximate element. Chloride of zinc is indeed a most energetic caustic, and requires to be employed with discretion. Full instructions respecting the manner of applying it are given in an article of mine on "Caustics and Cauterisation", which I published in the Cyclopredia of Surgery. It is especially useful in the instance of cancerous sores, accompanied with bleeding fungosities and fetid ichorous discharge. Ulcers of this nature, "the mere despair of surgery", have thus been brought to cicatrise. Although the cure be but fleeting, still a few months of calm and apparent health are no little boon to a patient so circumstanced.

I have likewise employed quick-lime as a caustic with good effect. It keeps up a kind of smouldering heat in the part. It is slower in its action, but productive of much less pain than the choride of zinc.

Case. A widow, fifty-eight years of age, of spare make and of sallow complexion, was sent to me by Dr. Spurgin, of Guildford Street, in April 1845. About a year previously she noticed a swelling, of the size of a hazel-nut, in the right breast, rather to the outer side, of a stony hardness, unattended with pain. After the lapse of six months, the incumbent skin became red and painful, and eventually gave way, the result being a discharge of ichorous fluid. The pain was of a shooting character. At the time of my seeing her, there was an ulcer, with an indurated base and narrow red circular border, evidently carcinomatous. It was about an inch in diameter. 'She complained of weakness; was free from cough. She had borne three children, and suckled them with both breasts indiscriminately. The catamenia had ceased in her fiftieth year. She lost an aunt from what was called " bleeding cancer". I applied the chloride of ninc paste; thereby eradicated the morbid growth, and procured a firm and healthy cicatrix. She was after this enabled to pursue her ordinary avocations.

Case. A few years ago, I was requested by Dr. Moore, of Savile Row, to see a lady who was suffering from secondary cancer. This lady was fifty-two years of age, of a full habit of body, and endowed with great mental and physical energy. Her left breast had been removed 
for scirrhus, by Mr. Green, three and a half years previously. In the cicatrix were two flattened tubercles. at some distance apart, slightly elevated above the adjunct skin, and having minute vessels ramifying over their surface. The larger of the two was about an inch in diameter. These tubercles were the seat of pain; and their presence was naturally a source of great anxiety to the patient and her friends. It was therefore determined that they should be removed by means of the chloride of sinc, which was done accordingly. This lady lived nearly four years afterwards in apparent comfort, mixing freely in society, from which she had previously withdrawn herself. She ultimately died of a sudden and rapid attack of disease of the chest, characterised, I was informed, by extreme difficulty of breathing, and great quickness of pulse.

CAsk. A married woman, sixty years of age, from the neighbourhood of Louth, in Lincolnshire, applied to me, several years since, respecting a tumour of the left breast. The patient had borne eleven children, and suckled them almost entirely with the right breast, because the left nipple had receded. Her complexion was ruddy, and her general health good. The tumour was about the size of a small apple, hard and nodulated, and the seat of stinging pain. The superincumbent skin was puckered in the centre, at which point the tumour was adherent. The disease was of two years' standing. She had, however, suffered more or less uneasiness in this breast for some years, and had been repeatedly subject to milk-abscess.

The patient was urgent to be relieved of the tumour by any means but the knife. I was reluctant to apply the chloride of zinc, on account of the amount of pain which would necessarily ensue, before a morbid growth of such extent could be eradicated. I therefore used quick-lime, and thus succeeded in removing the principal portion of the tumour. The quick-lime determined a progressive separation of the diseased mass in the form of moist, glutinous shreds, of a dark brown colour. The abstraction of the remainder was accomplished by a single application of the chloride of zinc paste. In six weeks, the resulting sore was cicatrised. She shortly afterwards returned to her native place, without any perceptible trace of induration in the breast.

After a lapse of six years, to my surprise, for I did not expect to find her then alive, she walked into my room, having come to town for the purpose of consulting me, on account of a recurrence of the cancer. An indurated patch, the size of a half-crown, the surface of which had a fine granular appearance, just as if it had been sprinkled with sand, occupied the cicatrix. It was the seat of occasional stabbing pain. She complained besides of pain and numbness in the left arm. The lymphatic glands, above the clavicle, were enlarged and indurated. She had a sallow unhealthy look; her appetite, however, continued good, and she had slept well till lately. It was not many months prior to the above date, that she had experienced any inconvenience, or noticed any change in the condition of the breast.

It was now manifest that the disease had relapsed in a form which was not to be benefited by surgical treatment. Yet, it is consolatory to think, that this patient obtained a respite from a painful malady for 
nearly sis years. What became of her subsequently, I lnow not. There can, however, be very little doubt that she died from the effects of cancerous cachexia.

With regard to general treatment, I would briefly observe, that the leading indication is to support the strength of the patient. M. Andral ascertained that one of the most constant effects of cancer, when it has lasted for some time, is a decrease of the globules of the blood. ${ }^{1}$ Now this is precisely what occurs in exhausting diseases. For this reason, all measures of depletion ought to be avoided, or used with the ntmost reserve, should any inflammatory ailment supervene. Benefit has been derived occasionally from the administration of cod-liver oil, alternated with chalybeates, should there be any tendency to anæmia.

\section{ON THE HEALTH OF LONDON DURING THE SIX MONTHS TERMINATING MARCH 27TH, 1852.}

By JOHN WEBSTER, M.D., F.R.S., Fellow of the Royal College of Physicians, Consulting Physician to St. George and St. James's Dispensary, etc.

TH в total number of deaths registered in London throughout the six months terminating at the end of last March, were nearly parallel in amount with those which took place during the two corresponding quarters of last year; showing that the late season has scarcely proved more than usually insalubrious. This general inference respecting the public health is fully borne out by comparing the number of deaths met with in all the metropolitan districts during both periods. Thus, in the six months ending March 27th, 1852, the gross mortality amounted to 28,445; whereas, in the parallel quarters of 1850 and 1851 , the number was 27,954, being an augmentation of 491 fatal cases, or about one and a half per cent in favour of the former, as compared with the more recent half-year. However, this increased rate of mortality was entirely confined to the months of October, November, and December, 1851 ; whilst a diminution of 1,929 deaths occurred during the quarter terminating last March; the comparative numbers being 14,481 in 1852 , against 15,410 in the first quarter of last year. It further merits special notice, that the above decrease of deaths appeared most remarkable during the last month of the period now quoted; the total mortality recorded during March 1851 was 5,478 , contradistinguished to 4,787 throughout the similar four weeks of the current year; thus giving 691 fewer deaths. The actual result

1 Essai d'hématologie pathologique. Paris: 1843. 